\title{
Does Face Consciousness Affect Tourist Behaviour at Festival Events? A Korean Perspective
}

\author{
Kyung-Yur Lee $(\mathbb{D})$ and Sang-Hyeon Park *(1) \\ Department of Tourism and Airline Management, Hanyang Cyber University, Seoul 04763, Korea; \\ kyungyur@gmail.com \\ * Correspondence: happy365@hycu.ac.kr; Tel.: +82-2-2290-0451
}

Citation: Lee, K.-Y.; Park, S.-H. Does Face Consciousness Affect Tourist Behaviour at Festival Events? A Korean Perspective. Sustainability 2021, 13, 11558. https://doi.org/ $10.3390 /$ su132011558

Academic Editor: Ans Vercammen

Received: 22 September 2021

Accepted: 16 October 2021

Published: 19 October 2021

Publisher's Note: MDPI stays neutral with regard to jurisdictional claims in published maps and institutional affiliations.

Copyright: (c) 2021 by the authors. Licensee MDPI, Basel, Switzerland. This article is an open access article distributed under the terms and conditions of the Creative Commons Attribution (CC BY) license (https:// creativecommons.org/licenses/by/ $4.0 /)$.

\begin{abstract}
This study aimed to (1) investigate whether face consciousness (or chemyon) and playfulness affect tourist behaviour and tourist satisfaction at a festival event from a South Korean perspective and (2) identify the moderating effects of both the frequency of visits and overnight trips. Structural equation modelling was conducted with a sample of 506 adults. The outcomes indicated that face consciousness and playfulness positively influenced tourist behaviour at festival events. In turn, these impacts were conducive to tourist satisfaction. However, the results were either positive or negative depending on specific tourist behaviour. Moreover, revisit travellers and overnight travellers exerted significant moderating impacts between certain paths. The integrative model can provide objective data for destination marketers and event organisers to support the enhancement of festival events in the post-COVID-19 era. The originality of this study lies in the initial attempt to adapt face consciousness to amalgamate tourist behaviour at festival events.
\end{abstract}

Keywords: face consciousness; FoMO; playfulness; tourist behaviour; satisfaction

\section{Introduction}

Face consciousness is deemed a ubiquitous phenomenon as a universal cultural sociopsychological concept [1,2]. However, Northeast Asian countries, notably China, Japan, and Korea, which retain Confucian cultures, manifest strong face consciousness. These countries have undergone communism, industrialisation, and westernisation during the past 100 years; however, Confucian ideas and behaviours have remained over the past 500 years [3]. Face is such a multi-related social concept that it influences families, friends, or co-workers wherever relationships among people are emphasised [4]. Likewise, face consciousness exists when people are interested in issues such as etiquette at home, etiquette in the workplace, and fashion.

Tourists commonly show a lower sense of face consciousness among those who do not know them because travelling is an escape from everyday life that allows them to have leeway to act somewhat excessively. As a temporary escape from routine, tourist destinations tend to be perceived as areas outside the limits of moral behaviour, which implies that tourists can easily be tempted into deviant behaviour [5]. For example, individuals who are ordinarily reticent can transform into talking and laughing loudly at tourist destinations. In this context, tourists' deviant behaviours can provide individuals with a cathartic experience that relieves their suppressed emotions under face consciousness and assists them in living in a psychologically stable status when they return to their daily lives. Notably, festival events provide various performances, activities, food, and beverages all in one place; therefore, tourists can relax their alertness and enjoy festival offerings. Given social cognitive theory, personality traits and behaviour manifested in encountered environments are clearly related. How does individual face consciousness manifest behaviours in festival environments? Despite the critical role that face consciousness plays in elucidating interpersonal and intergroup behaviour [6], it is surprising that 
the causal association between face consciousness and tourist behaviour at festival events has remained underdeveloped in tourism research.

Meanwhile, this study enquires whether playfulness and face consciousness are antecedents among various factors that affect tourist behaviour at festivals. Many researchers have focused on playfulness. Researchers have developed different life cycle stages, for example, children [7], adults [8], adolescents [9], and older adults [10], and they have ascertained that there is a difference in individual behaviour depending on playfulness propensity [11]. Given this context, it is certain that playfulness propensity is highly related to behaviour at festival events; however, the relations between the two have not yet been illuminated and have received little attention from scholars. This research gap offers the impetus for our study.

Accordingly, here, the aim of this study is to ascertain whether face consciousness and playfulness affect tourist behaviour at a festival event from a Korean perspective. Furthermore, this study identifies the moderating roles of the frequency of visits and overnight trips. The originality of this study lies in its attempt to conceptualise an initial framework of face consciousness at a festival event to provide empirical support. Currently, large-scale gatherings have either been suspended or held online due to the extent of the coronavirus, but given the COVID-19 era, various events will soon resume for another leap forward by preventing and fortifying disinfection. Therefore, enquiry about the integrative model of face consciousness, playfulness, tourist behaviour, and satisfaction will theoretically enrich comprehensive knowledge regarding tourist psychology and its mechanisms, which can provide an understanding of tourist behaviour at festival events. Additionally, this integrative model can offer objective data for destination marketers and event organisers to thus support the enhancement of festival events in the post-COVID-19 era.

The next section provides a conceptual background of the pertinent literature to develop hypotheses. A set of research hypotheses were formulated, including main and moderating effects. The materials and methods were subsequently elucidated. The next section presents the study findings and discussion. The final section draws conclusions, offers theoretical, practical, and social implications, and proposes directions for further research.

\section{Literature Review}

\subsection{Face Consciousness, Playfulness, and Tourist Behaviour}

Comprehending personality can garner critical insights into tourist behaviour. Asians, specifically Korean, Chinese, and Japanese individuals, manifest their unique cultural psychological personality, which is face consciousness. Face is known as a sociopsychological phenomenon that engenders in all human society faction practice [2]; however, face is commonly a well-known manifestation of Northeast Asians [1]. Face can be gained or lost because it implies an individual's image, position, or prestige in a specific community [12]. Face consciousness is named chemyon in Korean, which is akin to the concepts of lian (face) and mianzi (image) in China and mentsu in Japan [13]. Face is defined as "the desire to be respected in interpersonal relationships" [14] (p. 5), and the term face is interchangeably used with face consciousness in the literature.

Understanding tourists' involvement in leisure tourist destinations can provide comprehensive knowledge of the dynamics of tourist behaviour [15]. Face has recently been addressed in elucidating tourists' behaviour in tourism studies, including tourists' consumption behaviour [16,17], package tours [1], travelling to prestigious destinations or luxury cruises [2,14], uncivilised behaviour [6], etc. Hyun and Han [14] reported that face consciousness had an important moderating role between similarity in other customer perceptions and social value, and this indicated that face consciousness elevated social value in luxury U.S. cruise travellers. Gao et al. [16] revealed that face influenced Chinese outbound group tourists' gift purchase behaviour, specifically the gift selection effect, brand orientation, and purchase cost. They also found that self-face influenced selection effort, brand orientation, and purchase cost much more strongly when a gift was given to a higher-status receiver. Kwek et al. [1] examined face and facework in Chinese shopping package tours 
using social exchange theory and suggested that diverse facework strategies appeared in between-group and within-group interactions. Zhang et al. [6] evinced that face exerted a significant impact on uncivilised behaviour and that the fear of losing collective face drove Chinese tourists to promote civilised behaviour. More recently, Naipeng et al. [2] explored the role of face in Chinese tourists' destination selection and travel behaviour, which resulted in travelling to prestigious destinations, purchasing luxury tourism merchandise, taking photos with famous landmarks, and further sharing travel pictures on social media because of their belief in gaining face.

Accordingly, previous studies have focused primarily on ostentatious proclivity in a relatively negative sense of face, investigated face by generally using a qualitative research methodology (except [2]), and mainly paid attention to Chinese mianzi. However, within the limited face consciousness study in tourism, the influences of face consciousness on tourists' behaviour are recognised, although no such relations have examined the connection between face consciousness and tourist behaviour in the festival event setting.

Meanwhile, face in Korea is used in two different components, according to Choi and Lee [18]. They proposed a model of a chemyon structure internalised by Koreans and further developed and evaluated a scale that measured the propensity of Koreans for chemyon-oriented behaviour. They indicated that constructive and defensive chemyon were engendered in face, which indicated that the two concepts were significantly correlated. They proposed that each face behaviour comprised personality integrity, ability, and authority as the main components and dual psychological processes embedded in the role of chemyon (see [18]).

Based on the literature review, we suppose that individuals who have face consciousness are likely to show different behaviours at festival events in front of others. Accordingly, we posit the following.

Hypothesis 1 (H1). Face consciousness is associated with tourist behaviour at festival events.

Playfulness is another personality trait that is just as ubiquitous among adults as it is among youngsters [19]. Glynn and Webster [8] defined playfulness as a propensity to define an activity in an imaginative, nonserious, or metaphoric manner to improve intrinsic enjoyment, engagement, and satisfaction. Those who have playful traits are uniquely able to transform de facto any environment to change it into a more entertaining setting [20]. The playfulness trait is associated with an intrinsic motivation felt by an individual in the pleasure drawn from the activity of play [21].

Playfulness traits have been addressed by many researchers for a long time. Lieberman [7] is known as the first researcher to propose the concept of playfulness as a trait manifested in the process of leisure activities or play. Shen, Chick, and Zinn [22] proposed playfulness in adulthood with five components. More recently, Cheng et al. [11] identified four factors of tour conductor playfulness, and a difference in individual behaviour exists depending on playfulness propensity.

People play various roles (e.g., mother, daughter, friend, or employee) in daily life, and each role generates different identities, which underpin individual self-definition [23]. Tourist destinations, specifically festivals, are convened temporally, and their promotionbased personalities engender mental images and expectations [24]. Social cognitive theory postulates clear relations between personality propensity and behaviour manifest in encountered environments. Gration, Raciti, and Arcodia [25] reported that festivalgoers strive to escape the realities of their normal existence in a cosy environment. Staged experiences in natural or constructed settings can create a more authentic sense of self (ideal self-image) [26]. Festivalscapes can be perceived as being in a destination where people can feel special and escape from the everyday mundane routine and work to a wholly different world [27]. Thus, we posited that tourist behaviour at festival events is likely to be different depending on playfulness traits.

Hypothesis 2 (H2). Playfulness traits are associated with tourist behaviour at festival events. 


\subsection{Tourist Behaviour at Festival Events and Tourist Satisfaction}

Tourist behaviour can be generated in two aspects: self-expression behaviour and overt behaviour in relation to others. Foremost, festivalgoers can express unusual behaviour in relatively negative ways, which is so-called deviant tourist behaviour. Li and Chen [28] explored Chinese tourists' perception of money and their vanity in deviant tourist behaviour. Their research resulted in the perception of money and vanity being positively correlated with deviant tourist behaviour, which includes littering on a tour, making too much noise in public, etc. Redmon [29] delineated that playful deviance at an urban tourist attraction offers enjoyment and self-validation for festival participants, which frames Erving Goffman's concept of backspaces. The author affirmed that backspaces offer a liminal permit for individuals to transgress norms while participating in playful deviance and revealing their secret selves in urban settings.

As previously mentioned, tourists' behaviour can also accompany consumption behaviour such as impulsive shopping [30] and souvenir purchase behaviour in Australia [16] and in the U.S. [17]. Meng et al. [30] indicated that impulsive, hedonic, and materialistic propensities of tourists generate impulsive urges and engagement in actual impulsive buying outbound trips to the U.S. among Chinese tourists. Xu and McGehee [17] delineated tourists' shopping behaviour in outbound trips to the U.S. in the important target of inbound market perspective. They confirmed that tourism provided a good opportunity for shopping because tourists have some leisure time while travelling and are away from their busy schedule in their home country.

In the latter stance, tourist-to-tourist interaction is a central part of a festival experience, and interactions between tourists exert an important effect on behaviour such as the desire to stay and satisfaction [31]. Tourist behaviour and interaction with other tourists or residents can generate emotional closeness [32]. Tourist-to-tourist interaction has been addressed in the academic literature, including group tours [33], backpacking [34,35], and cruise ships [36]; however, tourist behaviour between tourists or between tourists and residents remains under-researched, especially in the festival setting. It is critical to understand the self-perceptions of participants to develop appropriate promotionbased festival personalities, which further ensure festival success and sustainability [37]. Accordingly, it is sufficiently predictable for tourists to exhibit various self-expressions, which provides a form of identity that conveys symbolic meaning not only for themselves but also between attendees in the festival setting.

Satisfaction implies consumers' overall evaluation of their experience [38] and represents their subjective degree of positive feeling after participating in leisure activities [39]. A substantial amount of tourism research has addressed satisfaction as a consequence factor in the context of tourism, including festivals [40]. For instance, Lee et al. [27] explored festival visitors' experience with the festival environment and found that it significantly influenced their satisfaction, which led to loyalty. Lee and Lee [40] indicated that an escape experience at a cultural heritage festival exerted a positive influence on festival satisfaction. Based on the previously reviewed literature, we posit the following.

Hypothesis 3 (H3). Tourist behaviour at festival events exerts a significant influence on tourist satisfaction.

\subsection{The Moderators of the Frequency of Visits and Overnight Trips}

Numerous studies have indicated that tourists are not homogeneous and that they exhibit individual differences. In addition to demographic factors, tourists' behaviour has been segmented by cultural elements such as nationality [41], face consciousness [1,2], and visit-related characteristics, such as revisit travellers and overnight trips [42-44].

Lee and Kyle [45] identified the multifaceted conceptualisation of psychological commitment for segmenting three types of festival visitors in Texas in the U.S. They found three segments, which indicated that they differed in age, education, and past experience. Lee et al. [43] investigated the determinants of visitors' stay at local festivals, and they 
affirmed that overnight trips are of considerable importance in the tourism context due to tourists spending more money and a longer trip duration to enjoy tourism activities. Harrington et al. [42] explored the role of attribute performance on overall satisfaction in Oktoberfest in Germany that resulted in eleven attributes defined as satisfiers, two attributes defined as dissatisfiers, and three attributes defined as delighters. Interestingly, they controlled repeat visitors, and the number of times attending exerted a negative relationship with overall satisfaction.

$\mathrm{Xu}$ et al. [44] investigated the moderating effect of staying overnight and the difference in satisfaction between first-time travellers and experienced travellers in the case of travellers with casino visits in Macau. They found that staying overnight and traveller satisfaction were positively related and that an overnight stay moderated the relationship between travel experience and trip satisfaction. In addition, first-time travellers engendered lower satisfaction than experienced travellers, and they are likely to stay overnight at their tourist destinations. However, staying overnight did not exert a moderating effect on the paths between first-time visits and satisfaction, thereby indicating inconsistent results [44]. Based on previous studies, we posit that revisit vs. first visit and an overnight trip vs. a one-day trip are likely to moderate the paths among face consciousness, playfulness, and tourist behaviour.

Hypothesis 4 (H4). A revisit or first visit moderates the relationship among face consciousness, playfulness, and tourist behaviour.

Hypothesis 5 (H5). Overnight trips or one-day trips moderate face consciousness, playfulness, and tourist behaviour.

Based on the literature, this study presents a research model to analyse the relationship between face consciousness, playfulness, tourist behaviours, and tourist satisfaction at a festival event in Korea and the moderating roles of the frequency of visit and overnight trip, as shown in Figure 1.

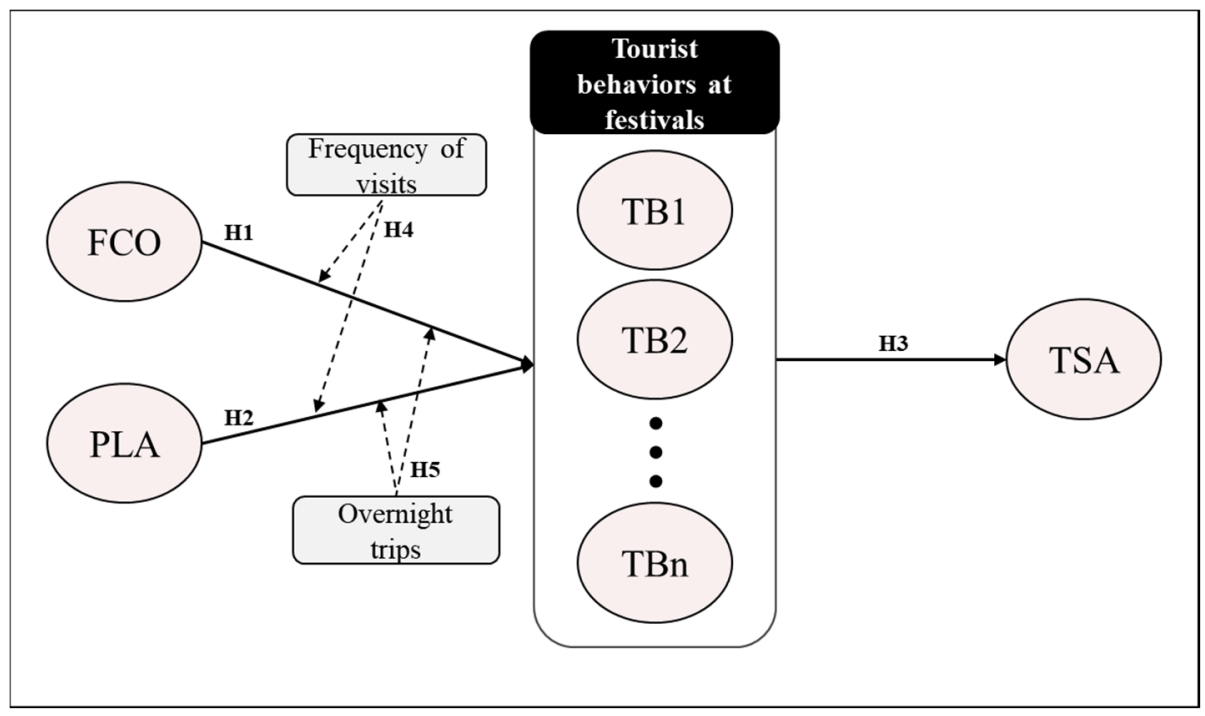

Figure 1. Research model. Notes: FCO: face consciousness, PLA: playfulness, TB: tourist behaviour, TSA: tourist satisfaction.

\section{Materials and Methods}

The statistical analysis of the data was performed by using structural equation modelling (SEM) with Windows SPSS and AMOS version 26.0. SEM provides a suitable analytical methodology due to its assessment of the structural relations among constructs in a holistic aspect. As Anderson and Gerbing [46] suggested, we employed a two-step 
statistical analysis approach. First, this study adopted a confirmatory factor analysis (CFA) of the empirical data to evaluate the validity of the constructs and estimates and whether the measurement error fits the conceptual model [47]. Second, we employed the structural model to conduct the path analysis.

The data analysis procedure was as follows. First, the descriptive statistics were analysed. Second, CFA was conducted, and third, the internal consistency of the derived factors was verified by using Cronbach's alpha. Fourth, a correlation matrix for the overall measurement model was assessed. Fifth, a path analysis was followed to ascertain the causal relationships. Finally, a multigroup analysis was performed to determine the moderating effects of both the frequency of visits and overnight trips.

Tourists were asked to answer a series of questions on the following five categories (see Appendix A). First, face consciousness was measured with five items by using scales developed by Choi and Lee [18] and Lee and Lee [48]. We referred to the Korean research measurement scale because the measurement scale of chemyon developed by Choi and Lee [18] has not been directly applied to festival event settings. Examples of face consciousness responses were 'I am conscious of the evaluation of others' and 'I am conscious how my appearance looks to others'. Second, playfulness was measured by using three items adapted from Shen et al. [22] and assessed with the following items: 'I try to have fun no matter what I am doing', 'I am often the person who starts fun things in a situation', and 'I can find fun in most situations.'

Third, given the lack of previous research on this specific tourist behaviour at festival events, an exploratory study was deemed appropriate. For this study, one of the authors first created the initial questions of tourist behaviour through a literature study. Then, in-depth interviews were conducted by using the free association questioning technique for the general public and festival specialists who had experience visiting a festival within the past year. The results were subjected to a content analysis and acquired three main categories and 16 subcategories as the initial items. The outcome of the qualitative research produced a 16-item pool as the basis for the development of tourist behaviour at festival events. The items were purified through an exploratory factor analysis in the field study according to the sequence of a preliminary survey and a main survey. Next, the reliability and validity of the scale were verified through CFA. Finally, three factors with 12 items were obtained as tourist behaviour at a water festival, namely, 'overacting behaviour', 'grooming behaviour', and 'social behaviour'. Overacting behaviour consisted of the four items of 'excessive drinking', 'overeating', 'overspending', and 'impulsive shopping'. Grooming behaviour subsumes four items, including 'putting on face paint and tattoos', 'putting on showy clothes', 'putting on hair decoration or a wig', and 'putting on heavy makeup'. Social behaviour includes four items, specifically, 'talking with other visitors whom I have never met before', 'singing with other visitors whom I have never met before', 'dancing with other visitors whom I have never met before', and 'watering other visitors'.

Fourth, three items were used to measure tourists' overall satisfaction [40]. An example of a satisfaction response was 'overall, I am very satisfied with this festival'. All of the questionnaire items were measured on a five-point Likert scale ( 1 = very unlikely, 5 = very likely). Finally, demographic variables (gender, age, marital status, educational level, and occupation) and visit-related characteristics (type of company, frequency of visit, and overnight trip) were collected.

The data were collected through a field survey at the 12th Jangheung Water Festival in South Korea in 2019. The rationales of selecting this festival as the sample of this study were as follow: (1) it is such a dynamic festival with a high escape experience, which uses water as a material, (2) and it is a nominated and certified festival that has been selected as one of the top-rated festivals in the country.

Before the actual survey, investigators were trained in the guidelines to avoid respondent bias. Interviewers, including one of the authors, conducted surveys under the big tent in front of the pool party places, and the survey respondents were asked if they participated in at least one water-related program at the festival. As a filtering question, 
questionnaire completion was discontinued unless the respondents had experienced a program at the festival.

The participants were assured of the anonymity of their answers and protection by Article 33 of the Statistical Act (protection of confidentiality) before beginning the actual process and then assured that their information would only be used for the research. Five hundred and twenty-nine respondents who participated in water programs at the festival completed a self-administered questionnaire on paper or a tablet PC. Listwise deletion was used [49]; therefore, twenty-three samples were excluded from analysis due to incomplete responses and outliers. This resulted in 506 usable data, which is a rate of $95.7 \%(55.9 \%$ female, mean age $=44.5)$. The sample size was applicable for testing SEM, which subsumed 23 latent variables, according to the criterion that at least 10 cases per variable are required for SEM [49].

\section{Findings}

Table 1 presents the survey participants' demographic profile and visit-related characteristics. The demographic profile sample showed that there were slightly more women (55.9\%) than men and more respondents aged 40 years (31.6\%) than other groups. Married individuals $(77.5 \%)$ dominated the sample. More than half had acquired a bachelor's degree $(58.9 \%)$. Regarding the visit-related characteristics, the majority of respondents came with family $(69.5 \%)$. Revisit travellers $(55.9 \%)$ were slightly more prevalent than first-time visitors $(44.1 \%)$, and overnight trips $(60.9 \%)$ were more prevalent than one-day trips $(39.1 \%)$.

Table 1. Demographic profiles and visit-related characteristics of the sample $(n=506)$.

\begin{tabular}{|c|c|c|c|c|c|}
\hline Variables & Items & $n(\%)$ & Variables & Items & $n(\%)$ \\
\hline \multirow{2}{*}{ Gender } & Man & $223(44.1)$ & \multirow{2}{*}{ Marital status } & Married & $392(77.5)$ \\
\hline & Woman & $283(55.9)$ & & Other & $114(22.5)$ \\
\hline \multirow{5}{*}{ Age (years) } & $20-29$ & $62(12.3)$ & \multirow{3}{*}{ Education level } & Highschool degree & $155(30.6)$ \\
\hline & $30-39$ & $112(22.1)$ & & Bachelor's degree & $298(58.9)$ \\
\hline & $40-49$ & $160(31.6)$ & & Over bachelor's degree & $53(10.5)$ \\
\hline & 50-59 & $106(20.9)$ & \multirow{6}{*}{ Occupation } & Office worker & $188(37.2)$ \\
\hline & 60 or older & $66(13.0)$ & & Self-employed & $70(13.8)$ \\
\hline \multirow{4}{*}{ Type of company } & Family & $352(69.5)$ & & Professional/researcher & $57(11.3)$ \\
\hline & Friends & $121(23.9)$ & & Housewife & $103(20.4)$ \\
\hline & Alone & $21(4.2)$ & & Student & $23(4.5)$ \\
\hline & Other & $12(2.4)$ & & Other & $65(12.8)$ \\
\hline \multirow{2}{*}{ Frequency of visits } & First visit & $223(44.1)$ & \multirow{2}{*}{ Overnight trip } & Yes & $198(39.1)$ \\
\hline & Revisit & $283(55.9)$ & & No & $308(60.9)$ \\
\hline
\end{tabular}

A CFA with the maximum likelihood estimation method was conducted to assess the validity and reliability of the scales that measured the concepts used in the research model, according to the two-step approach proposed by Anderson and Gerbing [46]. The resultant values indicated an adequate model fit. The CFA chi-square value was 590.839 with 215 degrees of freedom $(p<0.001, \mathrm{GFI}=0.907, \mathrm{IFI}=0.947, \mathrm{TLI}=0.937, \mathrm{CFI}=0.946$, and RMSEA $=0.059$ ). The TLI, IFI, and CFI values ranged from $0-1$, with an estimate close to 1.0, indicating an adequate level within the commonly accepted range [50]. An RMSEA value below 0.10 is acceptable, but values between 0.04 and 0.08 are considered to be good. Table 2 shows the specific measurement variables used in this study and their factor loading values. All factor loadings were statistically significant at the $p<0.001$ level, with $t$-values ranging from 8.783 to 28.747 . Although the one-factor loading in overacting behaviour was slightly below the level, we included the variable due to its significance in this research (i.e., overdrinking). The coefficients of internal consistency of each subscale (Cronbach's alpha) were analysed, confirming the criterion at an acceptable level of 0.70 . 
The findings indicated that the internal consistency was as follows: face consciousness ( $\alpha=0.931)$; playfulness $(\alpha=0.851)$; overacting behaviour $(\alpha=0.759)$; grooming behaviour $(\alpha=0.874)$; social behaviour $(\alpha=0.820)$; and tourist satisfaction $(\alpha=0.909)$. All factors met the criterion for acceptable internal reliability with a total $\alpha=0.873$.

Table 2. Confirmatory factor analysis and internal consistency.

\begin{tabular}{|c|c|c|c|c|}
\hline Constructs & Item & $\begin{array}{c}\text { Factor } \\
\text { Loading a }\end{array}$ & C.R. & $\begin{array}{c}\text { Cronbach's } \\
\alpha\end{array}$ \\
\hline \multirow{5}{*}{ Face consciousness (FCO) } & FCO 1 & 0.781 & $21.823 * * *$ & \multirow{5}{*}{0.931} \\
\hline & FCO 2 & 0.829 & $24.143^{* * *}$ & \\
\hline & $\mathrm{FCO} 3$ & 0.889 & $27.461^{* * *}$ & \\
\hline & FCO 4 & 0.903 & $28.313^{* * *}$ & \\
\hline & FCO 5 & 0.867 & - & \\
\hline \multirow{3}{*}{ Playfulness (PLA) } & PLA 1 & 0.809 & $17.326^{* * *}$ & \multirow{3}{*}{0.851} \\
\hline & PLA 2 & 0.899 & $17.938^{* * *}$ & \\
\hline & PLA 3 & 0.736 & - & \\
\hline \multirow{4}{*}{ Overacting behaviour (OVE) } & OVE 1 & 0.402 & $8.783^{* * *}$ & \multirow{4}{*}{0.759} \\
\hline & OVE 2 & 0.494 & $11.003^{* * *}$ & \\
\hline & OVE 3 & 0.901 & $18.071^{* * *}$ & \\
\hline & OVE 4 & 0.837 & - & \\
\hline \multirow{4}{*}{ Grooming behaviour (GRO) } & GRO 1 & 0.540 & $13.026^{* * *}$ & \multirow{4}{*}{0.874} \\
\hline & GRO 2 & 0.781 & $21.981 * * *$ & \\
\hline & GRO 3 & 0.939 & $28.747^{* * *}$ & \\
\hline & GRO 4 & 0.878 & - & \\
\hline \multirow{4}{*}{ Social behaviour (SOC) } & SOC 1 & 0.607 & $11.717 * * *$ & \multirow{4}{*}{0.820} \\
\hline & SOC 2 & 0.865 & $15.158^{* * *}$ & \\
\hline & SOC 3 & 0.843 & $14.991^{* * *}$ & \\
\hline & SOC 4 & 0.641 & - & \\
\hline \multirow{3}{*}{ Tourist satisfaction (TSA) } & TSA 1 & 0.934 & $25.300 * * *$ & \multirow{3}{*}{0.909} \\
\hline & TSA 2 & 0.882 & $24.072 * * *$ & \\
\hline & TSA 3 & 0.823 & - & \\
\hline
\end{tabular}

Notes: All factor loadings are significant at ${ }^{* * *} p<0.001 .{ }^{a}$ Loadings $<0.4$ were removed. Goodness-of-fit statistics of the total model: $\chi 2=590.839, \mathrm{df}=215, \mathrm{Q}(\mathrm{CMIN} / \mathrm{df})=2.748, p<0.001, \mathrm{GFI}=0.907, \mathrm{IFI}=0.947$, $\mathrm{TLI}=0.937, \mathrm{CFI}=0.946, \mathrm{RMSEA}=0.059$, total $\alpha=0.873 . \mathrm{GFI}=$ goodness-of-fit index, NFI $=$ normed fit index, IFI = incremental fit index, CFI = comparative fit index, TLI $=$ Tucker-Lewis index, RMSEA = root-mean-square error of approximation.

As shown in Table 3, to check the overall associations among the study's latent variables, a correlation matrix was assessed, which revealed that most variables were correlated and that no correlation coefficients $(\gamma)$ exceeded 0.435 . The average variance extracted (AVE) for all variables was greater than the 0.5 cut-off, which supported acceptable convergent validity. The composite reliability (CR) of all the variables was higher than 0.840 , which was above the 0.70 threshold value (ranging from 0.840 to 0.942 ) and indicated that all of the constructs in the research model had acceptable internal consistency [46].

Table 3. Descriptive statistics and associated measures.

\begin{tabular}{|c|c|c|c|c|c|c|c|c|c|}
\hline & $\begin{array}{l}\text { Number of } \\
\text { Items }\end{array}$ & $\begin{array}{c}\text { Mean } \\
\text { (Std. Deviation) }\end{array}$ & AVE & FCO & PLA & OVE & GRO & SOC & TSA \\
\hline $\mathrm{FCO}$ & 5 & $2.69(0.86)$ & 0.751 & $0.942^{a}$ & & & & & \\
\hline PLA & 3 & $3.59(0.73)$ & 0.668 & $-0.099 * b$ & 0.857 & & & & \\
\hline OVE & 4 & $2.70(0.82)$ & 0.558 & $0.133^{* *}$ & $0.134^{* *}$ & 0.840 & & & \\
\hline GRO & 4 & $2.01(0.84)$ & 0.648 & $0.198^{* *}$ & 0.043 & $0.384^{* *}$ & 0.903 & & \\
\hline SOC & 4 & $2.67(0.98)$ & 0.498 & $0.142^{* *}$ & $0.310^{* *}$ & $0.352 * *$ & $0.435^{* *}$ & 0.853 & \\
\hline TSA & 3 & $4.02(0.72)$ & 0.776 & -0.006 & $0.330 * *$ & $0.176^{* *}$ & 0.022 & $0.309 * *$ & 0.912 \\
\hline
\end{tabular}

Notes: * Correlations are significant at the 0.05 level. $2 .{ }^{* *}$ Correlations are significant at the 0.01 level. FCO: face consciousness, PLA: playfulness, OVE: overacting behaviour, GRO: grooming behaviour, SOC: social behaviour, TSA: tourist satisfaction. AVE = average variance extracted.

${ }^{a}$ Composite reliabilities are found along the diagonal line of bold entries. ${ }^{b}$ Correlations are found below the diagonal line. 
As shown in Table 4, the results of the research hypothesis test showed that the model fit index was $\mathrm{Q}(\mathrm{CMIN} / \mathrm{df})=3.442, p=0.000, \mathrm{GFI}=0.879, \mathrm{CFI}=0.923, \mathrm{IFI}=0.923, \mathrm{TLI}=0.912$, and $\mathrm{RMSEA}=0.070$. All values were consistent with the statistical criteria; therefore, the proposed model was adequate. According to the squared multiple correlation (SMC) value, the variance explained by face consciousness and playfulness for total tourist behaviour was $30.6 \%$, and the variance explained by tourist behaviour for tourist satisfaction was $16.8 \%$.

Table 4. Results of the structural model.

\begin{tabular}{cccccc}
\hline \multirow{2}{*}{ H } & & Hypothesised Association & $\begin{array}{c}\text { Std. } \\
\text { Estimate }\end{array}$ & t-Value & Results \\
\hline \multirow{3}{*}{$\mathrm{H} 1$} & $\mathrm{H} 1 \mathrm{a}$ & $\mathrm{FCO} \rightarrow$ OVE & 0.178 & $3.429^{* * *}$ & Supported \\
& $\mathrm{H} 1 \mathrm{~b}$ & $\mathrm{FCO} \rightarrow \mathrm{GRO}$ & 0.228 & $4.837^{* * *}$ & Supported \\
& $\mathrm{H} 1 \mathrm{c}$ & $\mathrm{FCO} \rightarrow \mathrm{SOC}$ & 0.193 & $4.110^{* * *}$ & Supported \\
\hline \multirow{3}{*}{$\mathrm{H} 2$} & $\mathrm{H} 2 \mathrm{a}$ & $\mathrm{PLA} \rightarrow$ OVE & 0.177 & $3.296^{* * *}$ & Supported \\
& $\mathrm{H} 2 \mathrm{~b}$ & $\mathrm{PLA} \rightarrow \mathrm{GRO}$ & 0.103 & $2.144^{*}$ & Supported \\
& $\mathrm{H} 2 \mathrm{c}$ & $\mathrm{PLA} \rightarrow$ SOC & 0.379 & $7.045^{* * *}$ & Supported \\
\hline \multirow{3}{*}{$\mathrm{H} 3$} & $\mathrm{H} 3 \mathrm{a}$ & OVE $\rightarrow$ TSA & 0.130 & $2.701^{* *}$ & Supported \\
& $\mathrm{H} 3 \mathrm{~b}$ & GRO $\rightarrow$ TSA & -0.153 & $-3.417^{* * *}$ & Supported \\
& $\mathrm{H} 3 \mathrm{c}$ & SOC $\rightarrow$ TSA & 0.360 & $7.134^{* * *}$ & Supported \\
\hline
\end{tabular}

Notes: ${ }^{* *} p<0.001,{ }^{* *} p<0.01,{ }^{*} p<0.05$. Goodness-of-fit statistics of the total model: $\chi 2=760.621, \mathrm{df}=221$ $\mathrm{Q}(\mathrm{CMIN} / \mathrm{df})=3.442, p<0.001, \mathrm{GFI}=0.879, \mathrm{NFI}=0.895, \mathrm{IFI}=0.923, \mathrm{TLI}=0.912, \mathrm{CFI}=0.923, \mathrm{RMSEA}=0.070$ GFI = goodness-of-fit index, NFI = normed fit index, IFI = incremental fit index, CFI = comparative fit index, $\mathrm{TLI}=$ Tucker-Lewis index, RMSEA = root-mean-square error of approximation. FCO: face consciousness, PLA: playfulness, OVE: overacting behaviour, GRO: grooming behaviour, SOC: social behaviour, TSA: tourist satisfaction.

Figure 2 provides the results of the estimated structural model with the standardised path coefficients. The path model analysis showed that Hypothesis 1 was significantly associated as we posited. Interestingly, face consciousness had positive (+) impacts on tourist behaviour at festivals. The path coefficient of face consciousness and overacting behaviour was $0.178(p<0.001)$, that of face consciousness and grooming behaviour was $0.228(p<0.001)$, and that of face consciousness and social behaviour was $0.193(p<0.001)$.

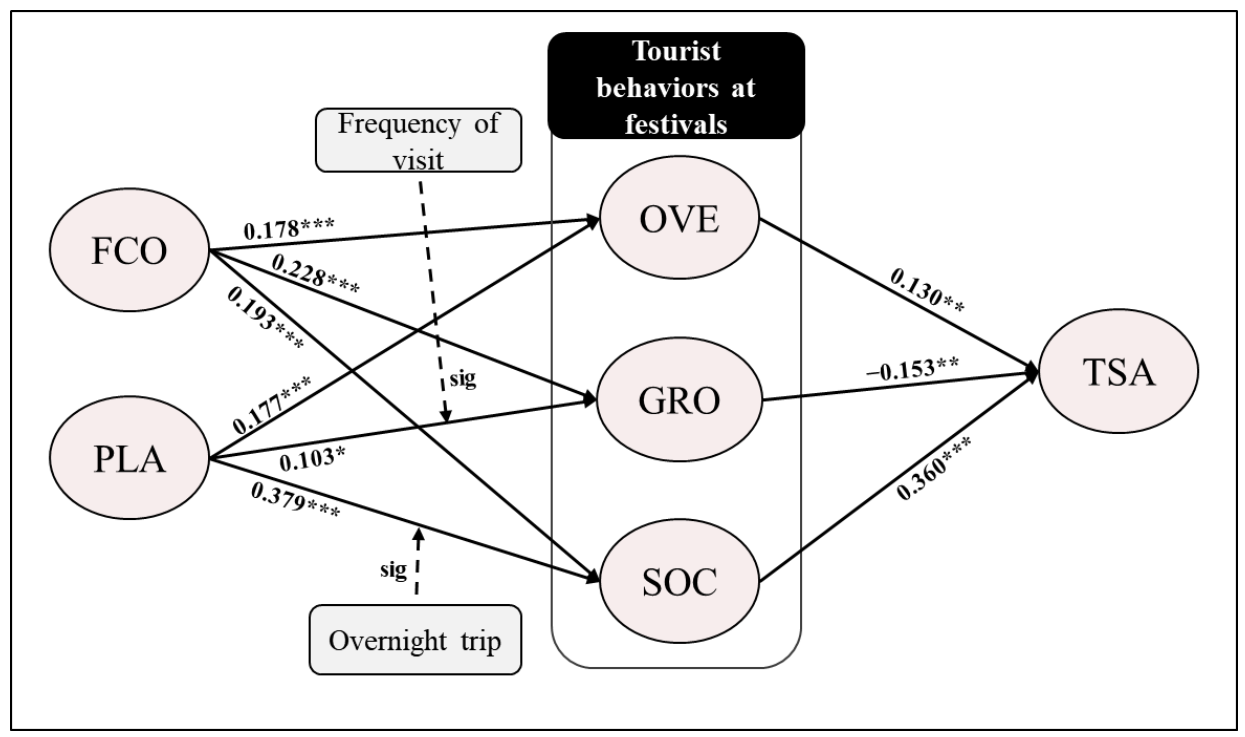

Figure 2. Results of the estimated structural model. Notes: ${ }^{* * *} p<0.001,{ }^{* *} p<0.01,{ }^{*} p<0.05$. sig: significant, FCO: face consciousness, PLA: playfulness, OVE: overacting behaviour, GRO: grooming behaviour, SOC: social behaviour, TSA: tourist satisfaction.

Hypothesis 2 was confirmed, as playfulness had a positive $(+)$ effect on all tourist behaviours. The path coefficient of playfulness and overacting behaviour was 0.177 
$(p<0.001)$, that of playfulness and grooming behaviour was $0.103(p<0.05)$, and that of playfulness and social behaviour was $0.379(p<0.001)$.

Hypothesis 3 was also supported; specifically, Hypotheses 3a and 3c were positively supported, while Hypothesis $3 \mathrm{~b}$ was negatively supported. The path coefficient of overacting behaviour and satisfaction was $0.130(p<0.01)$ and that of social behaviour and satisfaction was $0.360(p<0.001)$. Grooming behaviour had a negative $(-)$ impact on tourist satisfaction (Hypothesis $3 \mathrm{~b}$ ), and the path coefficient was $-0.153(p<0.01)$.

A multigroup analysis was conducted to analyse the moderating roles. The moderating role of the frequency of visits in the relationship among face consciousness, playfulness, and tourist behaviour was assessed (Hypothesis 4). The samples were divided into two groups (first visit $=1, n=223$; revisit $=0, n=283$ ). The cross-group equality constraints method was used to test the hypotheses on the basis of the chi-square $\left(\chi^{2}\right)$ difference between the constrained and unconstrained models by identifying the difference in the degrees of freedom. As a result of comparing the chi-square of the two groups, only the path from playfulness to grooming behaviour was significant at the 0.05 level $\left(\chi^{2}(1)=5.772\right.$, $p=0.017)$, which partially supports Hypothesis 4 . This result indicates that the effect of playfulness on grooming behaviour is significantly different between first visitors and revisit travellers. Regarding revisit travellers, the path coefficient was $0.186(p<0.001)$. In contrast, for the first visit travellers, the path coefficient was not significant $(\beta=-0.040$, $p=0.616$ ). Accordingly, playfulness was found to be effective in improving grooming behaviour at festival events for revisit travellers (Table 5).

Table 5. Results of the moderating role of the frequency of visits.

\begin{tabular}{lcccccc}
\hline \multicolumn{2}{c}{ Hypothesis 4} & First visit $(\beta)$ & Revisit $(\beta)$ & Constraints & $\Delta \chi^{2}$ & Status \\
\hline H4a & FCO $\rightarrow$ OVE & 0.201 & 0.162 & $\chi^{2}(629)=1448.430$ & $\Delta \chi^{2}(1)=0.101$ & Not supported \\
H4b & FCO $\rightarrow$ GRO & 0.306 & 0.188 & $\chi^{2}(629)=1449.587$ & $\Delta \chi^{2}(1)=1.258$ & Not supported \\
H4c & FCO $\rightarrow$ SOC & 0.269 & 0.162 & $\chi^{2}(629)=1449.767$ & $\Delta \chi^{2}(1)=1.438$ & Not supported \\
H4d & PLA $\rightarrow$ OVE & 0.235 & 0.112 & $\chi^{2}(629)=1449.295$ & $\Delta \chi^{2}(1)=0.966$ & Not supported \\
H4e & PLA $\rightarrow$ GRO & -0.040 & 0.186 & $\chi^{2}(629)=1454.101$ & $\Delta \chi^{2}(1)=5.772 *$ & Supported \\
H4f & PLA $\rightarrow$ SOC & 0.292 & 0.452 & $\chi^{2}(629)=1450.572$ & $\Delta \chi^{2}(1)=2.242$ & Not supported \\
\hline
\end{tabular}

Notes: ${ }^{*} p<0.05 . \chi^{2}(628)=1448.329(p=0.000), \chi^{2} / \mathrm{df}=2.306, \mathrm{RMR}=0.109, \mathrm{GFI}=0.826$, IFI = 0.904, CFI = 0.903, RMSEA = 0.051. FCO: face consciousness, PLA: playfulness, OVE: overacting behaviour, GRO: grooming behaviour, SOC: social behaviour.

Finally, the moderating function of overnight trips among face consciousness, playfulness, and tourist behaviour was assessed (Hypothesis 5). The samples were divided into two groups (overnight trip $=1, n=198$; one-day trip $=0, n=308$ ). Likewise, as a result of comparing the chi-square of the two groups, only the path from playfulness to social behaviour was significant at the 0.05 level $\left(\chi^{2}(1)=4.232, p=0.041\right)$, thus partially supporting Hypothesis 5 . This outcome indicates that the effect of playfulness on social behaviour is significantly different between overnight and one-day travellers. For overnight trips, the path coefficient was $0.462(p<0.001)$, and for one-day trips, the path coefficient was 0.330 $(p<0.001)$. Thus, playfulness was found to be effective in improving social behaviour at festival events for overnight travellers (Table 6).

Table 6. Results of the moderating role of overnight trips.

\begin{tabular}{lcccccc}
\hline \multicolumn{2}{c}{ Hypothesis 5} & $\begin{array}{c}\text { Overnight } \\
\text { Trip }(\boldsymbol{\beta})\end{array}$ & $\begin{array}{c}\text { One-Day } \\
\text { Trip }(\boldsymbol{\beta})\end{array}$ & Constraints & $\Delta \chi^{2}$ & Status \\
\hline H5a & FCO $\rightarrow$ OVE & 0.204 & 0.147 & $\chi^{2}(629)=1410.160$ & $\Delta \chi^{2}(1)=0.058$ & Not supported \\
H5b & FCO $\rightarrow$ GRO & 0.228 & 0.216 & $\chi^{2}(629)=1410.154$ & $\Delta \chi^{2}(1)=0.052$ & Not supported \\
H5c & FCO $\rightarrow$ SOC & 0.140 & 0.237 & $\chi^{2}(629)=1410.886$ & $\Delta \chi^{2}(1)=0.783$ & Not supported \\
H5d & PLA $\rightarrow$ OVE & 0.150 & 0.208 & $\chi^{2}(629)=1410.320$ & $\Delta \chi^{2}(1)=0.218$ & Not supported \\
H5e & PLA $\rightarrow$ GRO & 0.069 & 0.130 & $\chi^{2}(629)=1410.221$ & $\Delta \chi^{2}(1)=0.119$ & Not supported \\
H5f & PLA $\rightarrow$ SOC & 0.462 & 0.330 & $\chi^{2}(629)=1414.334$ & $\Delta \chi^{2}(1)=4.232 *$ & Supported \\
\hline
\end{tabular}

Notes: ${ }^{*} p<0.05 . \chi^{2}(628)=1410.103(p=0.000), \chi^{2} / \mathrm{df}=2.245, \mathrm{RMR}=0.115, \mathrm{GFI}=0.828, \mathrm{IFI}=0.908, \mathrm{CFI}=0.907$, RMSEA = 0.050. FCO: face consciousness, PLA: playfulness, OVE: overacting behaviour, GRO: grooming behaviour, SOC: social behaviour. 


\section{Discussion of Results}

This study identified that face consciousness and playfulness affected tourist behaviour and tourists' satisfaction at a festival event. Specifically, face consciousness exerted a positive influence on tourist behaviour at a festival. As outbound trips generate impulsive shopping [30] and luxury souvenir purchase behaviour [16,17], the festival setting in our study induced visitors to spend more. Face consciousness is related to the fear of missing out (FoMO) regarding the sense of being conscious of others to avoid falling behind others. The psychological term FoMO has been used in elucidating a psychological state where individuals become anxious that others are leading more interesting and socially decent lives [51]. Our finding is partially supported by Kang et al.'s [52] outcome, in which FoMO induced culturally associated brand consumption behaviour. Redmon [29] argued that backspaces provide a liminal permit for individuals to reveal their secret selves; however, Korean festival venues are unlikely to be sufficient to reveal participants' secret selves. Face consciousness was positively associated with social behaviour (e.g., 'talking with other visitors whom I have never met before'), which supports Woosnam and Norman's [32] contention that interaction with tourists or residents can generate emotional closeness.

Playfulness exerted a positive influence on tourist behaviour at a festival (Hypothesis 2). Predictably, the playfulness trait manifested more in the festival setting than in ordinary time, which supports Shen et al.'s [22] argument that playfulness increasingly crosses the borders of leisure and work and causes tension release. When attendees had a greater playfulness propensity, they were more likely to show all constructs of the tourist behaviours.

Tourist behaviour at festivals exerted a significant impact on tourist satisfaction (Hypothesis 3). According to the result of Hypothesis 3c, the atmosphere at the water festival stimulated a positive interplay with other customers; therefore, social behaviour must have generated a cocreation among the attendees in our study, which demonstrates the third generation of the experience economy, that is, customer-to-customer cocreation [53]. Alexiou [54] evinced characteristics of all three generations of the experience economy (i.e., first, experience staged by the firm; the second, cocreation experience between the service provider and the customer; and third, cocreation experience among customers), which were found at the festival. Recently, culturally favourable behaviour has been increasingly important for sustainable tourist behaviour [55]. Therefore, our finding is partially consistent with Chandran et al.'s [55] study that people are interested in visiting local places for interaction with local people, which in turn, affected satisfaction as tourists.

Grooming behaviour exerted a negative influence on tourist satisfaction. One possible explanation for this finding could be the cultural aspect whereby, in Korean social spheres, a complex conflation among face consciousness, collectivism, and FoMO exists. Grooming behaviour is not a negative behaviour but a behaviour that can appear naturally at any festival. However, it seems to be a behaviour that is still difficult for Korean culture to permit. Meanwhile, the mean value of grooming behaviour was below the median value $(M$ grooming behaviour $=2.01)$. Notably, such a result may appear because the questionnaire was completed while the respondents were conscious of other people's grooming behaviour. In this vein, the study outcome is partially associated with Borgers et al.'s [56] finding that assessment of others' emotions makes tourists' decision to return to the destination.

The result of a multigroup analysis on the moderating effect of the frequency of visits showed that revisit travellers exerted a moderating effect between playfulness and grooming behaviour. Indeed, this study's finding indicated that the travellers with high playfulness traits revealed more grooming behaviour, which indicates that repeat travellers elevated such behaviour. The festivalscape affects positive (e.g., happy, energetic, and excited) emotion and ultimately visitor satisfaction [27]. Accordingly, it is rational that the travellers with a higher playfulness propensity can elevate grooming behaviour when they revisit due to positive emotions and a familiar festivalscape.

Additionally, this study identified that the moderating effect of overnight travellers exerted a significant effect between playfulness and social behaviour. The outcome of this result is partially in accordance with $\mathrm{Xu}$ et al. [44], who found that an overnight stay 
heightens trip satisfaction for those with casino experience. Accordingly, strategies based on increasing overnight travellers are needed to induce more interaction with visitors, which will ultimately generate more tourists' satisfaction.

\section{Conclusions, Implications, and Future Directions}

The primary purpose of this study was to investigate whether face consciousness and playfulness affect tourist behaviour and tourists' satisfaction at a festival event. We notably focused on the relationship between face consciousness and an event destination. The resultant constructs from the SEM path analysis identified a causal relationship at a festival in Korea. The main findings are as follows.

First, face consciousness exerted a positive influence on overacting, grooming, and social behaviour at the festival. More specifically, when visitors had greater face consciousness, they revealed more tourist behaviours at the festival. Face consciousness per se is being conscious of other visitors at the tourist destination, and the festival setting is sufficient to engender tourists' overacting behaviour, such as overspending and impulsive shopping. The most interesting finding was that face-conscious tourists had heightened grooming behaviour, which is different from what we thought. It is a common idea that individuals with low face consciousness show more grooming behaviour. Grooming behaviour consisted of decorating behaviours (e.g., putting on face paint, tattoos, and heavy makeup); thus, we supposed that face consciousness would alleviate these behaviours in traditional Korean society. Our findings indicated that Korean face consciousness manifested differently than other cultures, and this finding can be interpreted by the psychosocial perspectives of FoMO, as we elucidated in the discussion section.

Second, playfulness was positively related to tourist behaviour. In this context, when the attendees had a greater playfulness propensity, they were more likely to reveal all constructs of the tourist behaviours.

Third, tourist behaviour exerted a significant impact on tourist satisfaction. Specifically, overacting behaviour and social behaviour positively influenced tourist satisfaction, whereas grooming behaviour negatively affected tourist satisfaction. The most surprising finding was that grooming behaviour exerted a negative impact on tourist satisfaction.

Finally, the moderating roles of both the frequency of visits and overnight trips were examined. According to the findings, revisits moderated the paths between playfulness and grooming behaviour, and no other paths exerted a significant effect. Additionally, overnight travellers moderated the paths between playfulness and social behaviour, and no other paths exerted a significant effect. Therefore, we confirmed that playfulness heightens interplay with others when staying a longer term at the destination.

Theoretically, this study contributes to the tourism and festival literature in three ways. First, the primary contribution involves the role of face consciousness, which determines the psychosocial mechanisms of tourist behaviour and tourists' satisfaction, especially in a festival setting. Second, this study is an early study that elucidates tourists' psychosocial mechanisms of tourist behaviour and satisfaction and demonstrates the importance of face consciousness and playfulness. The study findings reported that face consciousness and playfulness were important determinants that affected tourist behaviour and tourists satisfaction at a festival event in Korea. No prior study has addressed these two variables in the festival tourism context. Thus, this study may provide innovative insight into festival research. Third, this research treats the frequency of visits and overnight trips as moderating variables, which exerted critical impacts between playfulness and certain tourist behaviours.

This study also provides three practical implications. The first critical implication for event organisers or festival planners is to break the stereotype that a high sense of face consciousness might impede social behaviour at a festival. Our findings showed that a high sense of face consciousness heightened even overacting, grooming, and social behaviour. In this vein, when planning festival programs, festival planners should place trained event organisers among visitors to create an interesting atmosphere as a trigger. For instance, 
Guests Organisers (G.O.) at Clubmed resort are trained to organise to eat, dance, and sing together to keep the visitors entertained.

Second, another connected implication is to heighten social behaviour and overacting behaviour to create positive satisfaction for visitors, which can be effective for festivals. It is natural that tourism industries should make more effort to improve their competitive advantage and provide an effective method for gathering tourists in various ways (e.g., preference pattern mining [57]). One potentially fruitful approach is that festival managers can prepare various and payable items to stimulate the purchase of festival souvenirs. Another example is holding a game or staging a surprising event where visitors can receive gifts while participating in the program.

Third, destination marketers should strive to invoke various strategies to increase loyal customers. This study found that the re-visit and overnight travellers with playful traits exerted a moderating effect that supports certain tourist behaviours. In this context, it will be helpful for marketing organisers to devise accommodation sharing platforms. One potential idealistic approach to enable both locals and travellers to be happy is that the houses of local residents can be temporarily rented during the festival period. As such, festivals can be considered to ultimately boost the local economy.

Regarding the social implications of this study, our findings report that Korean chemyon engendered behaviour at a festival is strongly associated with FoMO syndrome. As we mentioned previously, FoMO consists of a desire for belonging and fear of isolation [52]; face consciousness is related to FoMO regarding the sense of being conscious of others to avoid falling behind them. Although the study on the face consciousness of Korean festivalgoers gives it an Eastern point of view, our research brings globalisation to the foreground. As more people have been interested in participating in local or global festivals, travellers who attend festivals in other countries take into consideration each country's unique culture. As such, a new framework that includes face consciousness is proposed, and this can be this study's social contribution.

The originality of this study lies in the attempt to adapt face consciousness to amalgamate tourist behaviour at festival events. This early study substantiates that Korean face consciousness manifests differently than in other cultures. Prior studies have ascertained the relations between social psychology and tourist behaviour in various aspects; however, scarce research situates a specific focus on face consciousness, which is a noticeable cultural psychosocial personality trait in Asia, and has a particular pertinence to festival event settings there. This study addressed this paucity in the research by reporting that face consciousness and playfulness are important determinants that affect tourist behaviour and tourists' satisfaction at events.

As one of the limitations of this study, the mechanism of tourist behaviour was analysed by using face consciousness and playfulness only as facilitators. Since the explanatory power of the model was generally low, a precise causal analysis could be carried out in the future by controlling other exogenous variables that affect tourist behaviour. Another limitation is that the majority of respondents were married and with accompanying family members, which might be the lacuna between behaviour at home and behaviour when travelling and could cause social responsibility bias [58]. Further studies are needed to address this issue.

Future research may necessitate adapting the integrative model of our research to other festivals, such as the beer festivals and Mardi Gras, to address the mechanisms. This would test the generalisability of these particular results derived from a Korean water festival. Moreover, more work is needed to understand the psychology of consumers who participate in festival tourism.

Author Contributions: K.-Y.L. wrote the article and contributed to data collection. S.-H.P. proposed the research framework and revised the paper. All authors have read and agreed to the published version of the manuscript.

Funding: This research received no external funding. 
Institutional Review Board Statement: Not applicable.

Informed Consent Statement: Informed consent was obtained from all subjects involved in the study.

Data Availability Statement: Data are not publicly available, although the data may be made available on request from the corresponding author.

Conflicts of Interest: The authors declare no conflict of interest.

\section{Appendix A}

\begin{tabular}{|c|c|c|c|c|c|}
\hline Face consciousness & $\begin{array}{l}\text { Strongly } \\
\text { disagree }\end{array}$ & Disagree & Neutral & Agree & $\begin{array}{c}\text { Strongly } \\
\text { agree }\end{array}$ \\
\hline 1. I am conscious of the evaluation of others. & 1 & 2 & 3 & 4 & 5 \\
\hline 2. I am sensitive to what other people think of me. & 1 & 2 & 3 & 4 & 5 \\
\hline 3. I am conscious how my appearance looks to others. & 1 & 2 & 3 & 4 & 5 \\
\hline 4. I am conscious of other people's opinions. & 1 & 2 & 3 & 4 & 5 \\
\hline 5. I tend to watch other people's eyes. & 1 & 2 & 3 & 4 & 5 \\
\hline Playfulness & $\begin{array}{l}\text { Strongly } \\
\text { disagree }\end{array}$ & Disagree & Neutral & Agree & $\begin{array}{c}\text { Strongly } \\
\text { agree }\end{array}$ \\
\hline 1. I try to have fun no matter what I am doing. & 1 & 2 & 3 & 4 & 5 \\
\hline 2. I am often the person who starts fun things in a situation. & 1 & 2 & 3 & 4 & 5 \\
\hline 3. I can find fun in most situations. & 1 & 2 & 3 & 4 & 5 \\
\hline Overacting behaviour & $\begin{array}{l}\text { Strongly } \\
\text { disagree }\end{array}$ & Disagree & Neutral & Agree & $\begin{array}{c}\text { Strongly } \\
\text { agree }\end{array}$ \\
\hline 1. excessive drinking & 1 & 2 & 3 & 4 & 5 \\
\hline 2. overeating & 1 & 2 & 3 & 4 & 5 \\
\hline 3. overspending & 1 & 2 & 3 & 4 & 5 \\
\hline 4. impulsive shopping & 1 & 2 & 3 & 4 & 5 \\
\hline Grooming behaviour & $\begin{array}{l}\text { Strongly } \\
\text { disagree }\end{array}$ & Disagree & Neutral & Agree & $\begin{array}{c}\text { Strongly } \\
\text { agree }\end{array}$ \\
\hline 1. putting on face paint and tattoos & 1 & 2 & 3 & 4 & 5 \\
\hline 2. putting on showy clothes & 1 & 2 & 3 & 4 & 5 \\
\hline 3. putting on hair decoration or a wig & 1 & 2 & 3 & 4 & 5 \\
\hline 4. putting on heavy makeup & 1 & 2 & 3 & 4 & 5 \\
\hline Social behaviour & $\begin{array}{l}\text { Strongly } \\
\text { disagree }\end{array}$ & Disagree & Neutral & Agree & $\begin{array}{c}\text { Strongly } \\
\text { agree }\end{array}$ \\
\hline 1. talking with other visitors whom I have never met before & 1 & 2 & 3 & 4 & 5 \\
\hline 2. singing with other visitors whom I have never met before & 1 & 2 & 3 & 4 & 5 \\
\hline 3. dancing with other visitors whom I have never met before & 1 & 2 & 3 & 4 & 5 \\
\hline 4. watering other visitors & 1 & 2 & 3 & 4 & 5 \\
\hline
\end{tabular}

\section{References}

1. Kwek, A.; Wang, Y.; Weaver, D.B. Face and facework in ethnic Chinese shopping-intensive package tours: Dynamics and outcomes. Tour. Manag. 2019, 74, 396-407. [CrossRef]

2. Shen, C.C.; Loverio, J.P.; Chen, L.H. The role of face (mien-tzu) in Chinese tourists' destination choice and behaviors. J. Hosp. Tour. Manag. 2021, 48, 500-508.

3. Kwek, A.; Lee, Y.S. Chinese tourists and confucianism. Asia Pac. J. Tour. Res. 2010, 15, 129-141. [CrossRef]

4. Joy, A. Gift giving in Hong Kong and the continuum of social ties. J. Consum. Res. 2001, 28, 239-256. [CrossRef]

5. Berdychevsky, L.; Gibson, H.; Poria, Y. Women's sexual behavior in tourism: Loosening the bridle. Ann. Tour. Res. 2013, 42, 65-85. [CrossRef]

6. Zhang, C.X.; Pearce, P.; Chen, G. Not losing our collective face: Social identity and Chinese tourists' reflections on uncivilised behaviour. Tour. Manag. 2019, 73, 71-82. [CrossRef]

7. Lieberman, J.N. Playfulness and divergent thinking: An investigation of their relationship at the kindergarten level. J. Genet. Psychol. 1965, 107, 219-224. [CrossRef] [PubMed]

8. Glynn, M.A.; Webster, J. The adult playfulness scale: An initial assessment. Psychol. Rep. 1992, 71, 83-103. [CrossRef] 
9. Staempfli, M.B. Adolescent playfulness, stress perception, coping and well-being. J. Leis. Res. 2007, 39, 393-412. [CrossRef]

10. Yarnal, C.; Qian, X. Older-adult playfulness: An innovative construct and measurement for healthy aging research. Am. J. Play. 2011, 4, 52-79.

11. Cheng, T.M.; Chen, M.T.; Wu, C.H. Tour conductor playfulness: Conceptualizing and scale development. J. Travel Res. 2021, 60, 197-207. [CrossRef]

12. Teon, A. The Concept of Face in Chinese Culture and the Difference Between Mianzi and Lian. Available online: https://chinajournal.org/2017/02/25/the-concept-of-face-in-chinese-culture-and-the-difference-between-mianzi-and-lian/ (accessed on 11 September 2021).

13. Lin, T.A.O. Face Perception in Chinese and Japanese. Intercult. Commun. Stud. 2017, 26, 151-167.

14. Hyun, S.S.; Han, H. Luxury cruise travelers: Other customer perceptions. J. Travel Res. 2015, 54, 107-121. [CrossRef]

15. Santos, V.; Ramos, P.; Sousa, B.; Almeida, N.; Valeri, M. Factors influencing touristic consumer behaviour. J. Organ. Chang. Manag. 2021. [CrossRef]

16. Gao, H.; Huang, S.S.; Brown, G. The influence of face on Chinese tourists' gift purchase behaviour: The moderating role of the gift giver-receiver relationship. Tour. Manag. 2017, 62, 97-106. [CrossRef]

17. Xu, Y.; McGehee, N.G. Shopping behavior of Chinese tourists visiting the United States: Letting the shoppers do the talking. Tour. Manag. 2012, 33, 427-430. [CrossRef]

18. Choi, S.C.; Lee, S.J. Two-component model of chemyon-oriented behaviors in Korea: Constructive and defensive chemyon. J. Cross Cult. Psychol. 2002, 33, 332-345. [CrossRef]

19. Sutton-Smith, B. Piaget on play: A critique. Psychol. Rev. 1966, 73, 104-110. [CrossRef]

20. Barnett, L.A. The nature of playfulness in young adults. Pers. Individ. Differ. 2007, 43, 949-958. [CrossRef]

21. Starbuck, W.H.; Webster, J. When is play productive? Account. Manag. Inform. Tech. 1991, 1, 71-90. [CrossRef]

22. Shen, X.S.; Chick, G.; Zinn, H. Playfulness in adulthood as a personality trait: A reconceptualisation and a new measurement. J. Leis. Res. 2014, 46, 58-83. [CrossRef]

23. Stedman, R.C. Toward a social psychology of place: Predicting behavior from place-based cognitions, attitude, and identity. Environ. Behav. 2002, 34, 561-581. [CrossRef]

24. Getz, D. Festivals, Special Events, and Tourism; Van Nostrand Reinhold: New York, NY, USA, 1991.

25. Gration, D.; Raciti, M.; Arcodia, C. The role of consumer self-concept in marketing festivals. J. Travel Tour. Mark. 2011, $28,644-655$. [CrossRef]

26. Oakes, T. Get real! On being yourself and being a tourist. In Travels in Paradox: Remapping Tourism; Minca, C., Oakes, T., Eds.; Rowman and Littlefield Publishers: Oxford, UK, 2006; pp. 229-250.

27. Lee, Y.K.; Lee, C.K.; Lee, S.K.; Babin, B.J. Festivalscapes and patrons' emotions, satisfaction, and loyalty. J. Bus. Res. 2008, 61, 56-64. [CrossRef]

28. Li, T.; Chen, Y. The destructive power of money and vanity in deviant tourist behavior. Tour. Manag. 2017, 61, 152-160. [CrossRef]

29. Redmon, D. Playful deviance as an urban leisure activity: Secret selves, self-validation, and entertaining performances. Deviant Behav. 2003, 24, 27-51. [CrossRef]

30. Meng, F.; Zhang, P.; Li, H.; So, K.K.F. Modeling precursors of impulsive tourist shopping behavior: Evidence from long-haul Chinese outbound tourists. Int. J. Tour. Res. 2019, 21, 344-358. [CrossRef]

31. Sun, H.; Wu, S.; Li, Y.; Dai, G. Tourist-to-tourist interaction at festivals: A grounded theory approach. Sustainability 2019, 11, 4030. [CrossRef]

32. Woosnam, K.M.; Norman, W.C. Measuring residents' emotional solidarity with tourists: Scale development of Durkheim's theoretical constructs. J. Travel Res. 2010, 49, 365-380. [CrossRef]

33. Torres, E.N. The influence of others on the vacation experience: An ethnographic study of psychographics, decision making, and group dynamics among young travelers. J. Hosp. Mark. Manag. 2015, 24, 826-856. [CrossRef]

34. Sørensen, A. Backpacker ethnography. Ann. Tour. Res. 2003, 30, 847-867. [CrossRef]

35. Yin, C.; Poon, P. The impact of other group members on tourists' travel experiences: A study of domestic package tours in China. Int. J. Contemp. Hosp. Manag. 2016, 28, 640-658. [CrossRef]

36. Huang, J.; Hsu, C.H.C. The impact of customer-to-customer interaction on cruise experience and vacation satisfaction. J. Travel Res. 2010, 49, 79-92. [CrossRef]

37. D'Astous, A.; Colbert, F.; d'Astous, E. The personality of cultural festivals: Scale development and applications. Int. J. Arts Manag. 2006, 8, 14-23.

38. Mason, M.C.; Paggiaro, A. Investigating the role of festivalscape in culinary tourism: The case of food and wine events. Tour. Manag. 2012, 33, 1329-1336. [CrossRef]

39. Ko, Y.S.; Park, S.H.; Lee, K.Y. Railbike experience and tourist satisfaction. Int. J. Tour. Sci. 2018, 18, 65-74. [CrossRef]

40. Lee, K.Y.; Lee, H. Traditional costume experience at a cultural heritage festival. Tour. Manag. 2019, 32, 100555. [CrossRef]

41. Lee, C.K.; Lee, Y.K.; Wicks, B.E. Segmentation of festival motivation by nationality and satisfaction. Tour. Manag. 2004, 25, 61-70. [CrossRef]

42. Harrington, R.J.; von Freyberg, B.; Ottenbacher, M.C.; Schmidt, L. The different effects of dis-satisfier, satisfier and delighter attributes: Implications for Oktoberfest and beer festivals. Tour. Manag. Perspect. 2017, 24, 166-176. [CrossRef] 
43. Lee, K.H.; Alexander, A.C.; Kim, D.Y. A study of geographical distance groups on length of visitors' stay at local food festival destinations. J. Vacat. Mark. 2014, 20, 125-136. [CrossRef]

44. Xu, Y.; Zhang, Z.; Fong, D.K.C.; Law, R. Can staying overnight affect traveler satisfaction? Evidence from a gambling destination. Asia Pac. J. Tour. Res. 2018, 23, 907-923. [CrossRef]

45. Lee, J.; Kyle, G.T. Segmenting festival visitors using psychological commitment. J. Travel Res. 2014, 53, 656-669. [CrossRef]

46. Anderson, J.C.; Gerbing, D.W. Structural equation modeling in practice: A review and recommended two-step approach. Psychol. Bull. 1988, 103, 411-423. [CrossRef]

47. Hair, J.F.; Black, W.C.; Babin, B.J.; Anderson, R.E.; Tatham, R.L. Pearson new international edition. In Multivariate Data Analysis, 7th ed.; Pearson Education Limited Harlow: Essex, UK, 2014.

48. Lee, S.H.; Lee, H.R. The effect of social face sensitivity of hotel employee on job satisfaction: Focused on the mediating effects of self-esteem. J. Foodserv. Manag. 2012, 15, 29-52.

49. Kline, R.B. Principles and Practice of Structural Equation Modeling, 4th ed.; Guilford Publications: New York, NY, USA, 2015.

50. Byrne, B.M. Structural Equation Modeling with Mplus: Basic Concepts, Applications, and Programming, 2nd ed.; Routledge: New York, NY, USA, 2013.

51. Przybylski, A.K.; Murayama, K.; DeHaan, C.R.; Gladwell, V. Motivational, emotional, and behavioral correlates of fear of missing out. Comput. Hum. Behav. 2013, 29, 1841-1848. [CrossRef]

52. Kang, I.; Cui, H.; Son, J. Conformity consumption behavior and FoMO. Sustainability 2019, 11, 4734. [CrossRef]

53. Boswijk, A.; Thijssen, T.; Peelen, E. The Experience Economy: A New Perspective; Pearson Education: Amsterdam, The Netherlands, 2007.

54. Alexiou, M.V. Experience economy and co-creation in a cultural heritage festival: Consumers' views. J. Herit. Tour. 2020, 15, 200-216. [CrossRef]

55. Chandran, A.; Mandal, S.; Shanmugeshwari, M.; Nair, G.; Das, P.; Ramachandran, N.; John, E. Sustainable tourist behaviour: Developing a second order scale based on three destinations. Int. J. Tour. Res. 2021. [CrossRef]

56. Borges, A.P.; Vieira, E.; Lopes, J.M. Emotional intelligence profile of tourists and its impact on tourism. J. Qual. Assur. Hosp. Tour. 2021. [CrossRef]

57. Islam, M.R.; Abdul Kader Jilani, M.M.; Miah, S.J.; Akter, S.; Ulhaq, A. Discovering tourist preference for electing destinations: A pattern mining based approach. Asia Pac. J. Tour. Res. 2021, 26, 1081-1096. [CrossRef]

58. Holmes, M.R.; Dodds, R.; Frochot, I. At home or abroad, does our behavior change? Examining how everyday behavior influences sustainable travel behavior and tourist clusters. J. Travel Res. 2021, 60, 102-116. [CrossRef] 